\title{
Hanford Site Black-tailed Jackrabbit Monitoring Report for Fiscal Year 2013
}

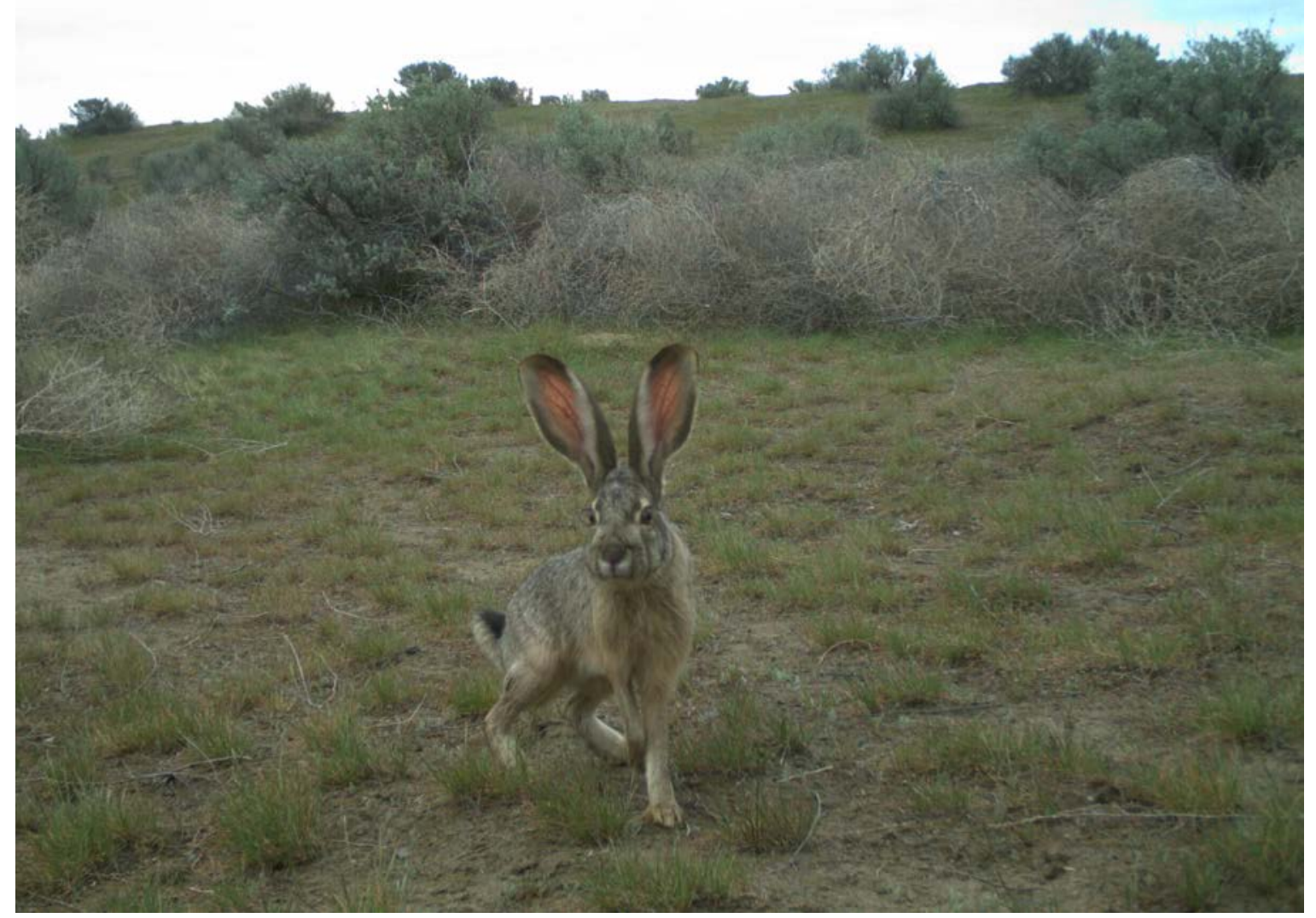

Prepared for the U.S. Department of Energy

Assistant Secretary for Environmental Management

Contractor for the U.S. Department of Energy

under Contract DE-AC06-09RL14728

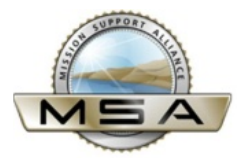

\section{P.O. Box 650}

Richland, Washington 99352 
HNF- 56710

Revision 0

TRADEMARK DISCLAIMER

Reference herein to any specific commercial product, process, or service by trade name, trademark, manufacturer, or otherwise, does not necessarily constitute or imply its endorsement, recommendation, or favoring by the United States Government or any agency thereof or its contractors or subcontractors.

This report has been reproduced from the best available copy.

Printed in the United States of America

The cover photo was taken with a motion-activated trail camera. 
HNF- 56710

\section{Hanford Site Black-tailed Jackrabbit Monitoring Report for Fiscal Year 2013}

C. Lindsey, J. Nugent, J. Wilde, and S. Johnson Mission Support Alliance

Date Published

February 2014

Prepared for the U.S. Department of Energy

Assistant Secretary for Environmental Management

Contractor for the U.S. Department of Energy

under Contract DE-AC06-09RL14728

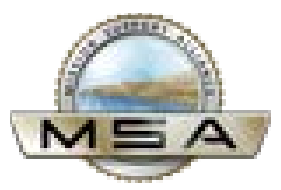

P.O. Box 650

Richland, Washington 99352

By Janis D. Aardal at 10:01 am, Feb 13, 2014 
HNF- 56710

Revision 0

\section{Contents}

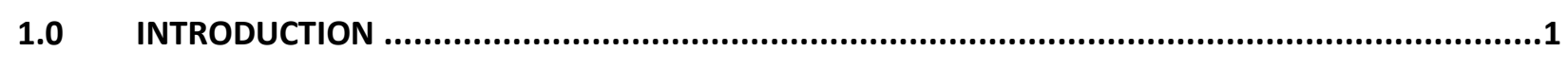

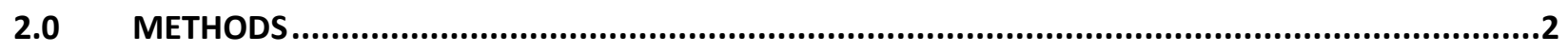

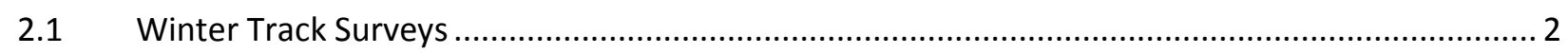

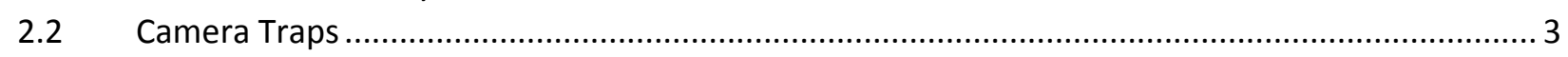

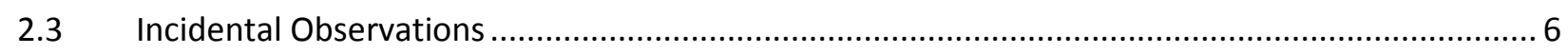

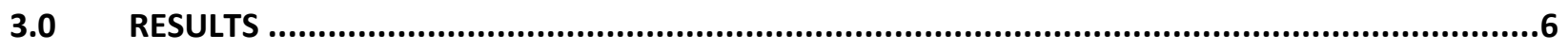

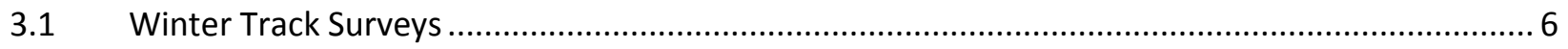

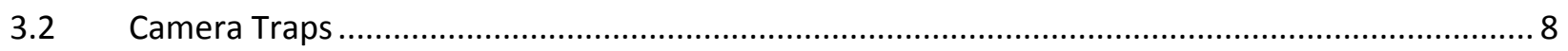

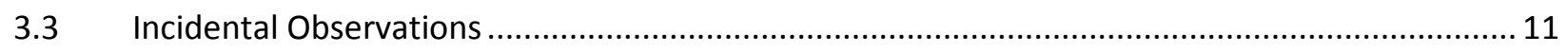

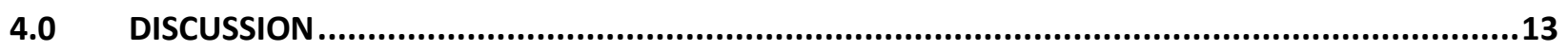

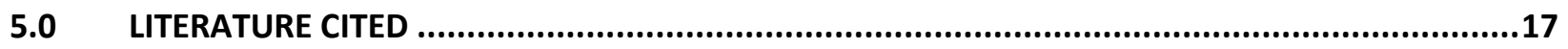

\section{Figures}

Figure 1. Survey Grid Developed for Camera Trap Surveys in 2013 …......................................................... 5

Figure 2. Trail Camera Deployed Along a Trail on the McGee-Riverlands Unit of the Hanford Site .................... 6

Figure 3. Snowfall Surveys Performed Across the Hanford Site in December 2012 ........................................ 7

Figure 4. Documenting Jackrabbit Tracks with GPS unit during Winter Track Surveys ...................................... 8

Figure 5. Hexagons Surveyed for Black-tailed Jackrabbits in 2013 ............................................................... 9

Figure 6. Number of Jackrabbit Observations by Time of Day Detected by All Trail Cameras ........................... 10

Figure 7. Black-tailed Jackrabbit Captured by a Trail Camera after Dark ........................................................ 10

Figure 8. Day the First Jackrabbit was Detected in Each Hexagon ............................................................... 11

Figure 9. Black-tailed Jackrabbit Sightings and Roadkills on the Hanford Site in 2013 .................................. 12

Figure 10. Hypothetical Jackrabbit Detection Probability Curve When Using Trail Cameras............................ 14

Figure 11. Adult and Juvenile American Badgers Photographed by a Trail Camera During 2013 ..................... 15 
HNF- 56710

Revision 0

\subsection{Introduction}

The U.S. Department of Energy, Richland Operations Office (DOE-RL) conducts ecological monitoring on the Hanford Site to collect and track data needed to ensure compliance with an array of environmental laws, regulations, and policies governing DOE activities. Ecological monitoring data provide baseline information about the plants, animals, and habitat under DOE-RL stewardship at Hanford required for decision-making under the National Environmental Policy Act (NEPA) and Comprehensive Environmental Response, Compensation, and Liability Act (CERCLA). The Hanford Site Comprehensive Land Use Plan (CLUP, DOE/EIS-0222-F) which is the Environmental Impact Statement for Hanford Site activities, helps ensure that DOE-RL, its contractors, and other entities conducting activities on the Hanford Site are in compliance with NEPA.

The Hanford Site Biological Resources Management Plan (BRMP, DOE/RL 96-32 Rev 1) is identified by the CLUP as the primary implementation control for managing and protecting natural resources on the Hanford Site. According to the CLUP, the BRMP

"provides a mechanism for ensuring compliance with laws protecting biological resources; provides a framework for ensuring that appropriate biological resource goals, objectives, and tools are in place to make DOE an effective steward of the Hanford biological resources; and implements an ecosystem management approach for biological resources on the Site. The BRMP provides a comprehensive direction that specifies DOE biological resource policies, goals, and objectives."

DOE-RL places priority on monitoring those plant and animal species or habitats with specific regulatory protections or requirements; or that are rare and/or declining (federal or state listed endangered, threatened, or sensitive species); or of significant interest to federal, state, or tribal governments or the public. The BRMP ranks wildlife species and habitats (Levels 0-5), providing a graded approach to monitoring biological resources based on the level of concern for each resource. Black-tailed jackrabbits (Lepus californicus) are ranked at Level 3, requiring a "moderate" level of monitoring according to BRMP.

Evidence suggests both black-tailed jackrabbits and white-tailed jackrabbits ( $L$. townsendii) were historically abundant in Washington (Ferguson and Atamian 2012). Jackrabbit populations are declining across Washington State due to the loss and fragmentation of the shrub-steppe habitat. The Washington State Department of Fish and Wildlife (WDFW) currently lists both the black-tailed and white-tailed jackrabbits as 'Candidates' for listing as Threatened or Endangered (WDFW 2012). Jackrabbits are infrequently sighted on the Hanford Site, potentially indicating population declines, while other factors such as natural population cycles may be contributing. To understand the extent and causes of this possible decline, and to implement means to protect the species, it is imperative to collect population status and distribution data before jackrabbits disappear completely from the Hanford Site. 
HNF- 56710

Revision 0

Black-tailed jackrabbits play an important role in the ecosystem, serving as a food source for large avian and mammalian predators including the coyote (Canis latrans), Golden Eagle (Aquila chrysaetos), and the State Threatened Ferruginous Hawk (Buteo regalis). Increasing the understanding of jackrabbits on the Hanford Site could benefit both common and sensitive predator species. Jackrabbits do not migrate long distances or go into a hibernation or estivation period. They also rarely use underground burrows or dens (Best 1996). The highly localized and active nature of jackrabbits provides surveying opportunities throughout the year.

Black-tailed jackrabbits prefer sagebrush-dominated habitats in Washington (PNL-8942). They also utilize rabbitbrush (Ericameria nauseosa and Chrysothamnus viscidiflorus) and antelope bitterbrush (Purshia tridentata) communities on the Hanford Site. White-tailed jackrabbits prefer grass-dominated habitats typically found at higher elevations in Eastern Washington, and have been observed on the Arid Lands Ecology Reserve (ALE). The DOE-RL managed portion of the Hanford Site consists of habitat more commonly associated with black-tailed jackrabbits. A combination of daytime walking transects and nighttime driving transects were conducted on the Hanford Site during FY2012 (HNF-54234). Other recent surveys on central Hanford consisted of driving surveys (TNC 1999). Although jackrabbits were detected using these methods, the data did not provide the information necessary to address occupancy and abundance of jackrabbits across the DOE-RL managed portion of the Hanford Site. Monitoring for FY2013 focused on the black-tailed jackrabbit on the DOE-RL managed portion of the Hanford Site using motion-activated trail cameras. Winter track counts were also planned contingent upon sufficient snowfall accumulation.

\subsection{Methods}

\subsection{Winter Track Surveys}

Winter track counts were dependent on sufficient snowfall accumulations. Surveys were performed along previously conducted driving survey routes (HNF-54234). Because of limited snowfall in FY2013, one survey was conducted on December 26, 2012. The survey was completed within 24 hours of snowfall for accurate documentation of activity levels. Surveyors drove 5-10 mph while observing both sides of the road for jackrabbit tracks. Upon discovering a set of tracks, surveyors stopped the vehicle and recorded the amount of jackrabbit sign observed entering or exiting the non-shrub covered portion of the roadway within $25-\mathrm{m}$ ahead of where the vehicle stopped. Trails were marked with a Global Positioning System (GPS) where the trail intersected the roadway and were categorized as single track, light trail (2-4 tracks), heavy trail (>4 tracks in single trail), light runway ( 2 trails converging or very near to one another) or heavy runway (>2 trails converging or very near to one another). This information was used to determine relative levels of activity and potential core areas for trail camera surveys. 
HNF- 56710

Revision 0

\subsection{Camera Traps}

Trail cameras were selected to survey for jackrabbits during FY2013. Traditional traps are labor intensive and intrusive to the animals, but trail cameras can be used as "camera-traps". The cameras capture photos of jackrabbits, confirming occupancy without interfering with the animal's normal behavior. The trail cameras could be placed in the field and left for several days without having to revisit the site, as opposed to traditional traps which have to be checked every 12 hours. This vastly reduced the level of effort per survey location.

The cameras used for this project were Recony ${ }^{\mathrm{TM}}$ PC900 HyperFire ${ }^{\mathrm{TM}}$ professional trail cameras. These cameras take color photos during the day and utilize an invisible infrared flash for unintrusive photographing at night. The camera is triggered when an object with a different temperature than the ambient temperature moves through the camera frame. Cameras were generally set on "high" trigger sensitivity, taking three photos per trigger 24 hours per day. No interval was used between photos ("Rapidfire" setting), and no quiet period was selected between trigger events. Each photo was time and date stamped.

The entire central Hanford Site was divided into a mesh of hexagonal survey areas measuring one square kilometer [0.39 square miles] using a geographic information system (GIS) (Figure 1). Hexagonal sample area size was based on the approximate size of a jackrabbit home range. Black-tailed jackrabbit home range size has been reported between 0.02 square kilometers and 1 square kilometer [0.01 to 0.39 square miles], and was $>0.5$ square kilometers [ $>0.19$ square miles] on the Hanford Site (Major 1993). The upper limit of the home range size was selected for this project so that a rabbit observed in one transect is assumed to not be present, and therefore not detectible, in any adjacent hexagon. This provides a coarser scale map of jackrabbit distribution, but also allows for a larger portion of the Hanford Site to be surveyed per-unit-effort. Trail cameras were used to definitively document the presence of jackrabbits within each hexagonal survey area.

A total of 820, one-square kilometer hexagons were identified across the DOE-RL managed portion of the Hanford Site (Figure 1). Surveying every hexagon would have been prohibitively time consuming, so initial camera setup locations were determined based on the presence of a black-tailed jackrabbit activity center, termed a "core area". These core areas are defined as areas with high levels of visibly detectible jackrabbit activity such as active trails and fresh scat. Jackrabbits were confirmed at core areas using the cameras, and then all adjacent hexagons were monitored using the camera setup. If any of the hexagons adjacent to the original core areas were found to contain jackrabbits, based on cameratrap observations, then the search area was expanded to include all hexagons adjacent to the newly discovered active hexagon. Cameras were not placed adjacent to hexagons where jackrabbits were not detected unless a new core area was identified. In this way, personnel avoided monitoring areas where jackrabbits were unlikely to be present, and focused on expanding the areas of known jackrabbit activity. 
HNF- 56710

Revision 0

Cameras were placed as near to the centroid of a hexagon as possible, with a maximum distance of 100 meters from the center. Keeping the cameras far away from the edges further minimized the chance of encountering the same individual in two adjacent hexagons. Field personnel surveyed the area around the centroid and identified the location where jackrabbit detection was most likely. These locations typically contained an active trail, scat, and trampled vegetation. When possible, the cameras were placed at the intersection of two or more active trails to maximize the potential for capturing photos of jackrabbits. If no active trails were present, natural funnels or other local environmental features were used to increase the potential for jackrabbit detection.

The cameras were placed on a tripod at approximately 50 centimeters high, and one to three meters from the focal point, with a slight downward tilt (Figure 2). Cameras were secured to available structures or shrubs using a cable lock. A Trimble ${ }^{\mathrm{TM}}$ GPS, capable of sub-meter accuracy, was used to acquire coordinates at the actual location of the camera setup, and data were recorded on a pre-made field data sheet including hexagon number, distance from centroid, distance from trail, camera direction, camera number, start time, and the vegetation type surrounding the camera. Cameras were left on-location for a minimum of three trap-nights, but deployments were typically one week. Cameras were then recovered and the photos were downloaded to the field GPS unit or laptop. Photos were reviewed to determine if jackrabbits were present in the hexagon. The same field data sheet used during deployment of the cameras was used during retrieval, and data collected included end time, total number of images, and whether jackrabbit presence was confirmed. 
HNF- 56710

Revision 0

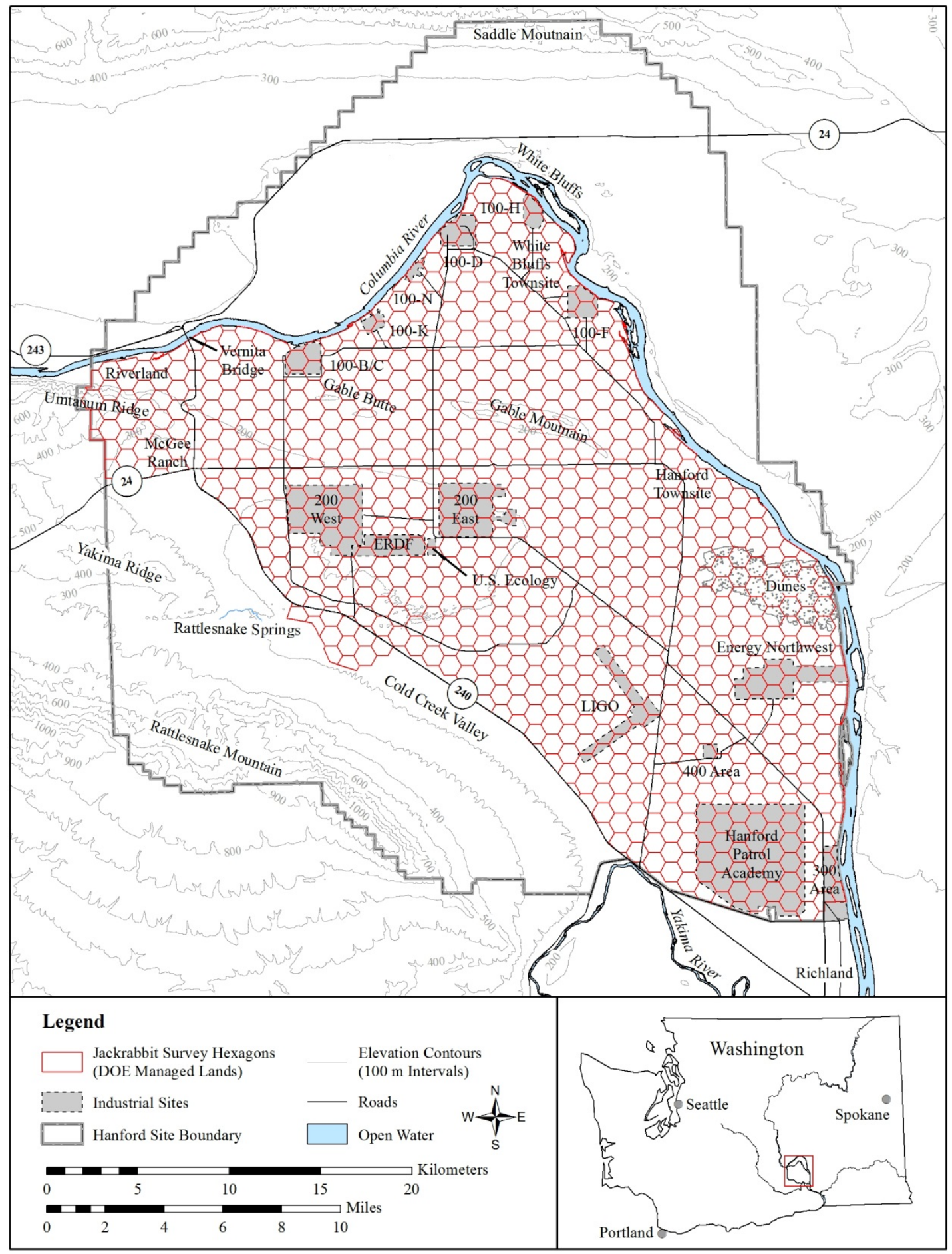

Figure 1. Survey Grid Developed for Camera Trap Surveys in 2013 


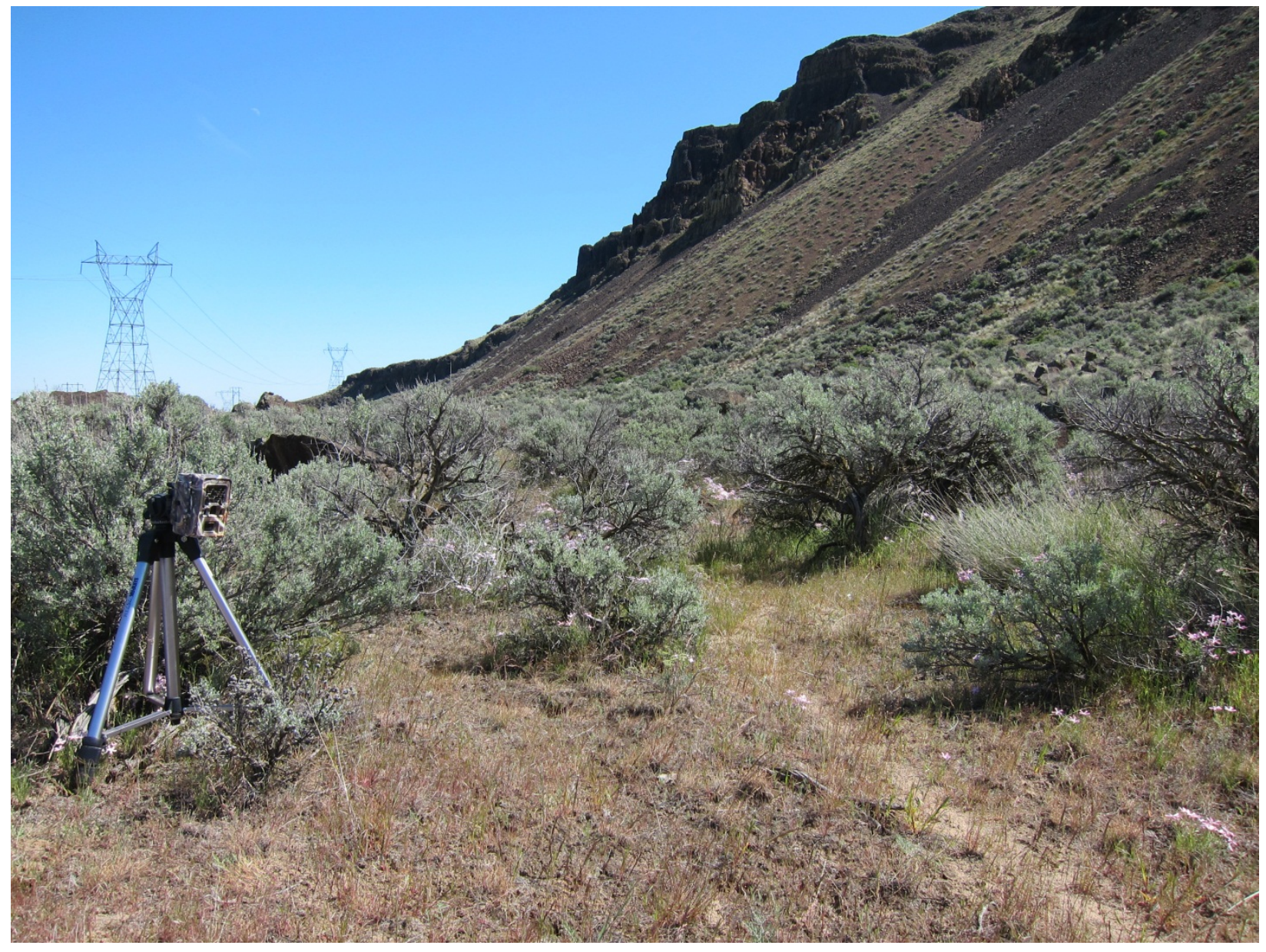

Figure 2. Trail Camera Deployed Along a Trail on the McGee-Riverlands Unit of the Hanford Site

\subsection{Incidental Observations}

All locations where jackrabbits were observed on the Hanford Site while setting trail cameras, driving, or performing other surveys were recorded. These included flushed individuals and roadkill observations. Locations were recorded using a GPS or the approximate location was marked on a map by the observer. All locations were stored using a GIS.

\subsection{Results}

\subsection{Winter Track Surveys}

Four winter track routes were surveyed on December 26, 2012 (Figure 3). The surveys were performed within 24 hours of the snowfall event. Jackrabbit tracks were documented on one route located north 
HNF- 56710

Revision 0

of Gable Mountain (Figure 4). A total of 23 trails were recorded from the North Gable Route including ten single trails, two light trails, one heavy trail, seven light runways, and three heavy runways.

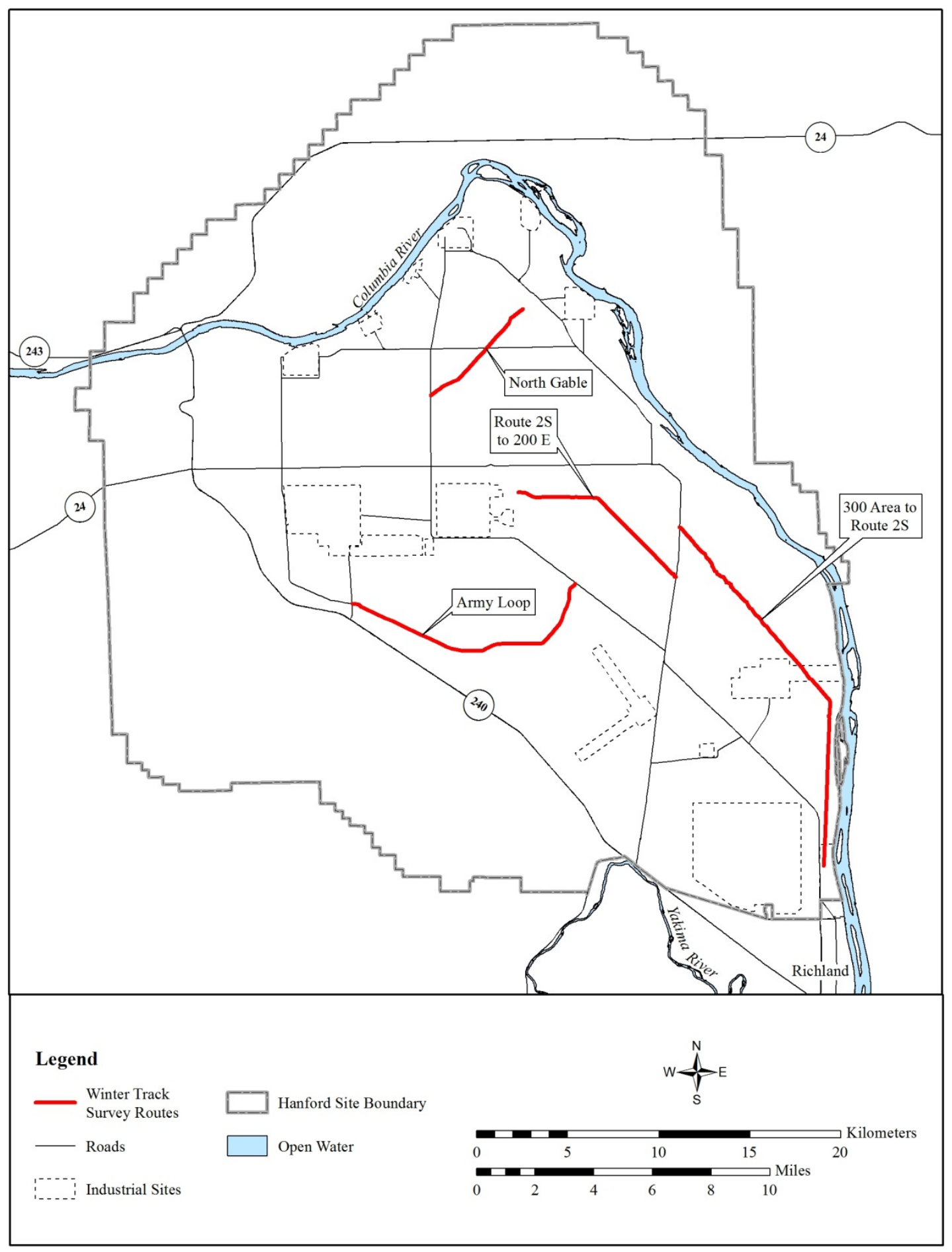

Figure 3. Snowfall Surveys Performed Across the Hanford Site in December 2012 
HNF- 56710

Revision 0

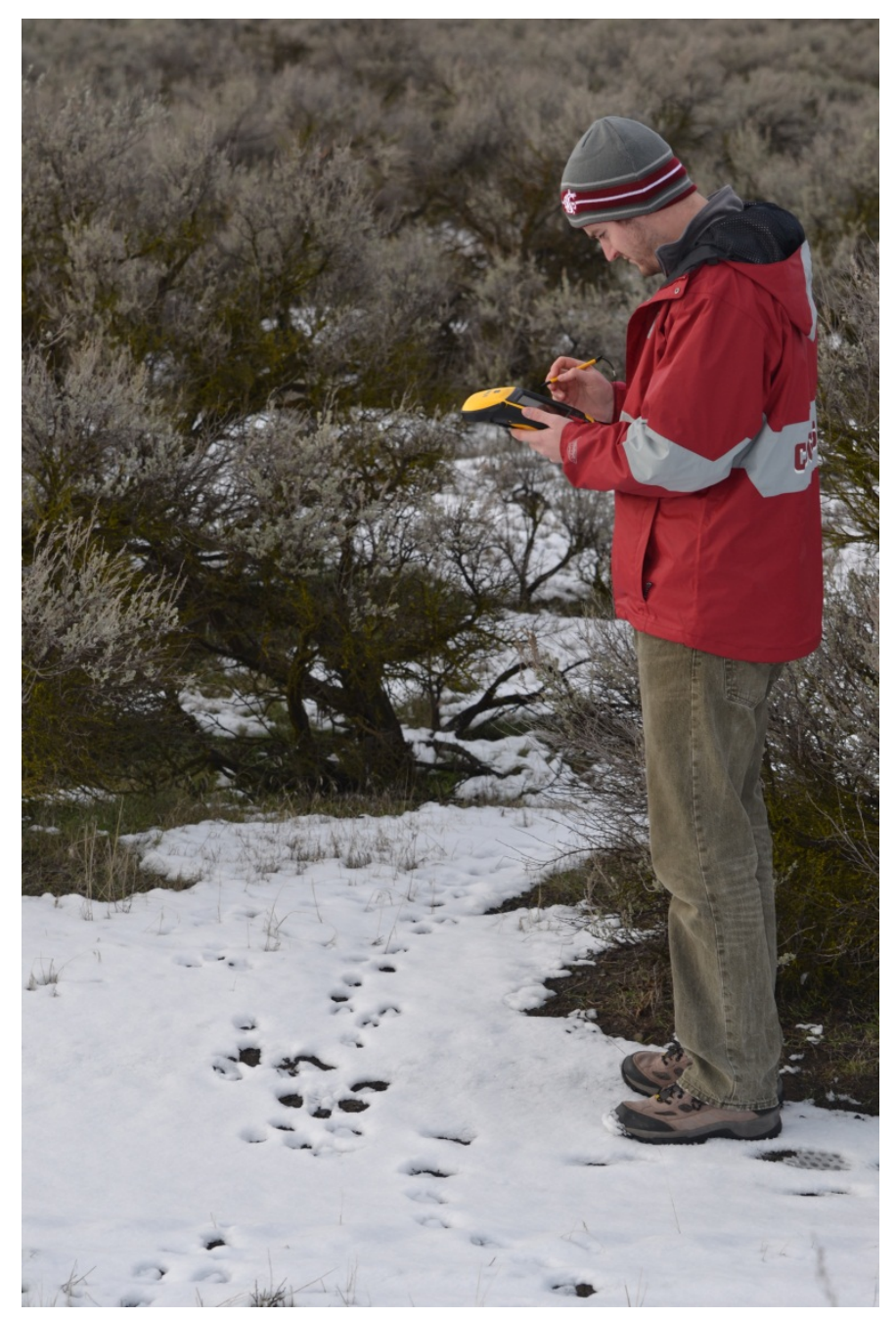

Figure 4. Documenting Jackrabbit Tracks with GPS unit during Winter Track Surveys

\subsection{Camera Traps}

Monitoring with trail cameras began on February 2, 2013, and the last FY2013 camera trap was retrieved on December 31, 2013. A total of 124 hexagons were completed in 2013 (Figure 5). Jackrabbits were detected within 45 of the hexagons surveyed. Between three and five cameras were deployed for the majority of the survey period with a total of 981 camera trap-nights recorded. The majority of detections were made after dark (Figure 6), and jackrabbits were readily identifiable even in photos taken at night (Figure 7). 
HNF- 56710

Revision 0

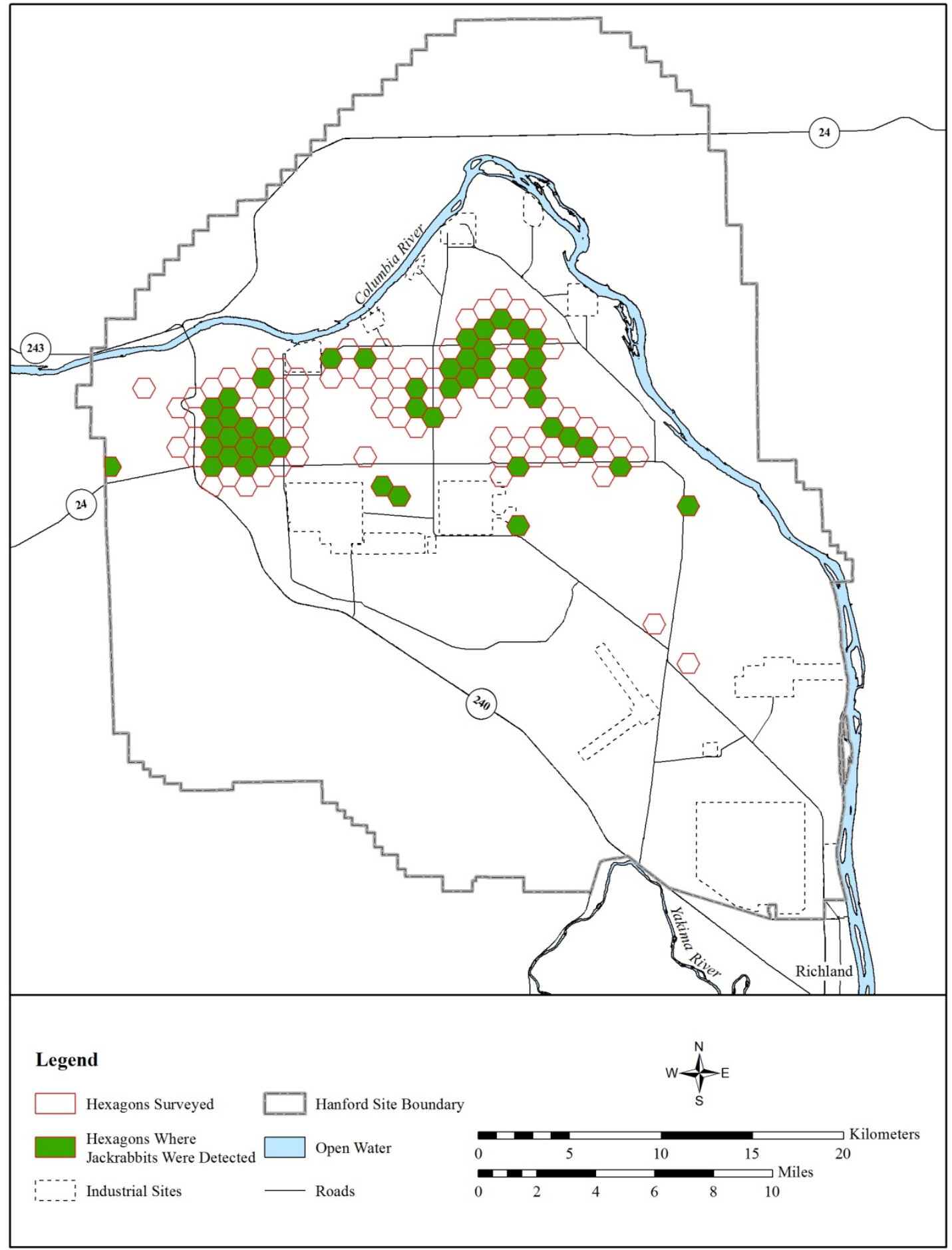

Figure 5. Hexagons Surveyed for Black-tailed Jackrabbits in 2013 


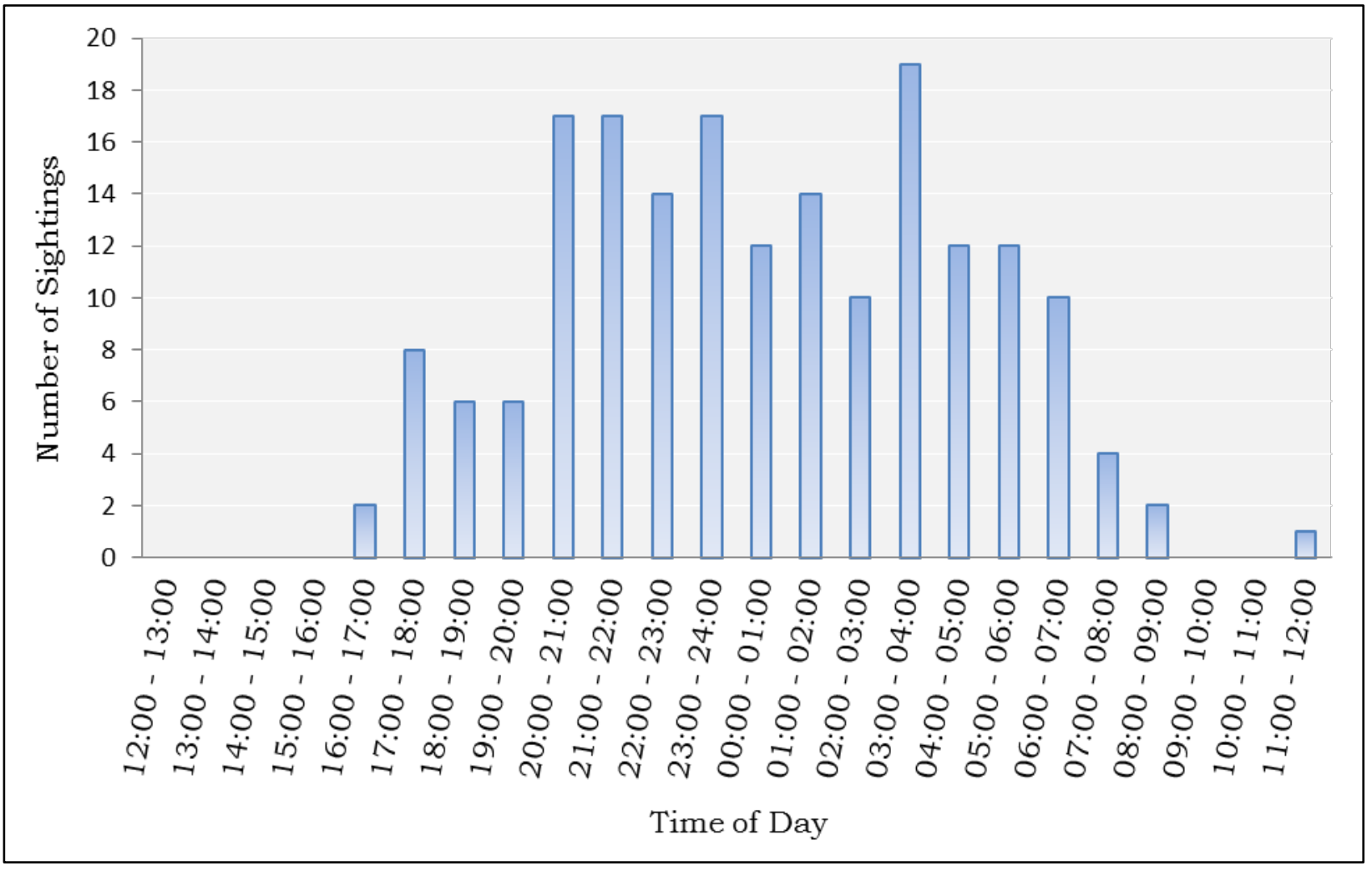

Figure 6. Number of Jackrabbit Observations by Time of Day Detected by All Trail Cameras

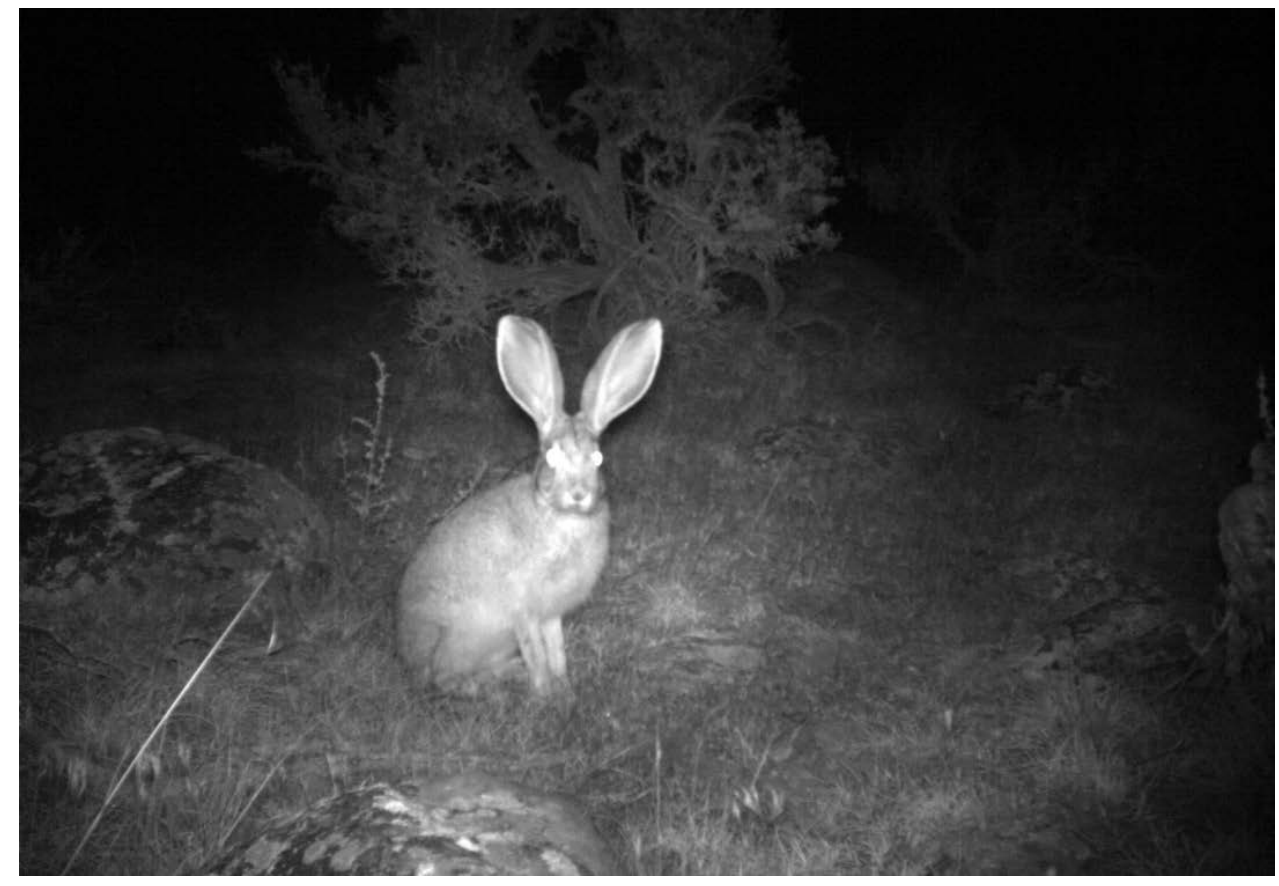

Figure 7. Black-tailed Jackrabbit Captured by a Trail Camera after Dark 
HNF- 56710

Revision 0

Trail cameras recorded the time of each photo taken, capturing the time when a black-tailed jackrabbit was first spotted in a given hexagon as well as subsequent detections. Using the trail camera data collection technique described above, project staff was able to monitor the success rate of jackrabbit detection and also to document the time it took from camera deployment to first detection of a jackrabbit. The time until the first jackrabbit was detected by the trail cameras in each hexagon is shown in Figure 8.

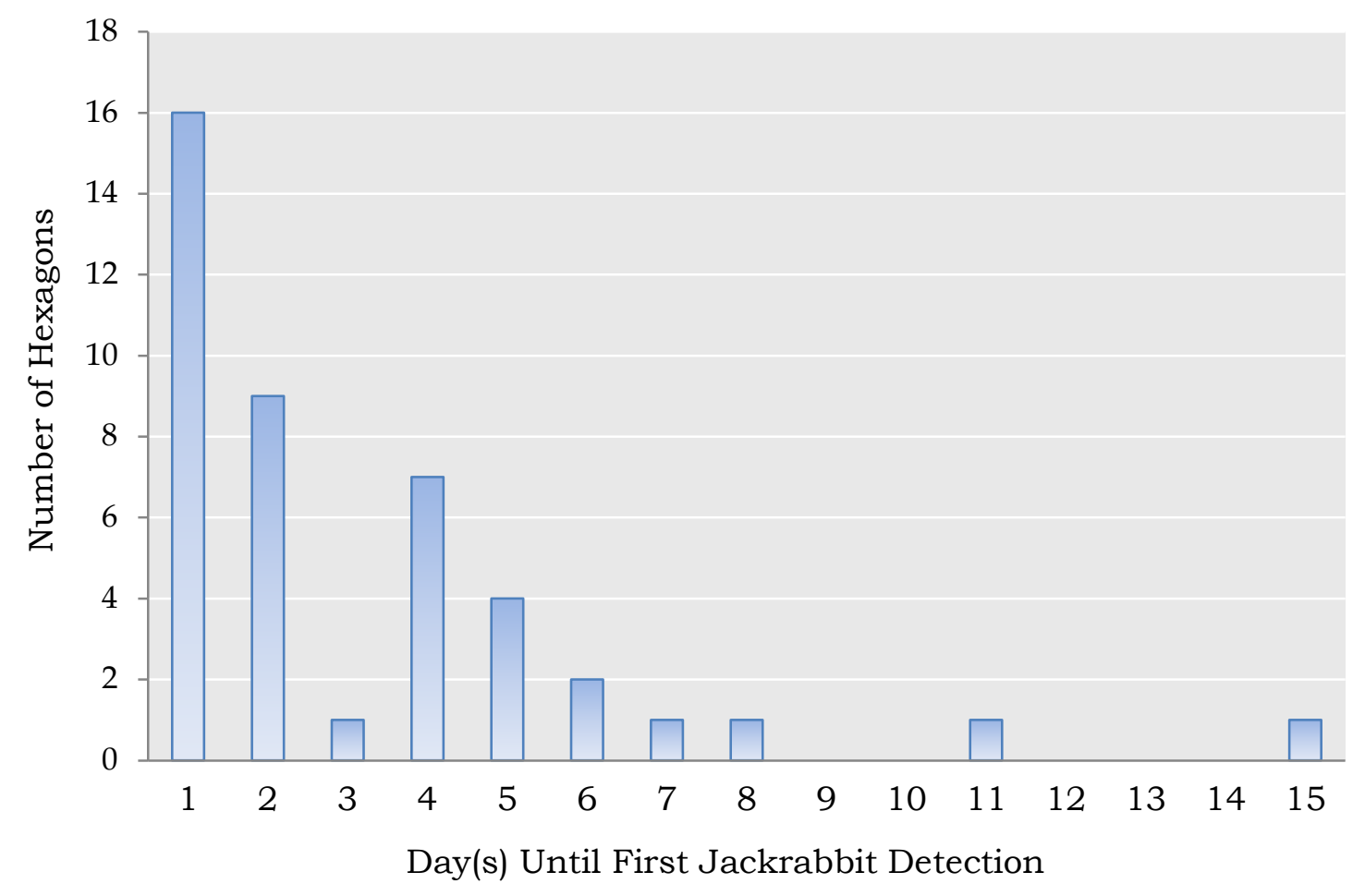

Figure 8. Day the First Jackrabbit was Detected in Each Hexagon

\subsection{Incidental Observations}

Incidental observations of black-tailed jackrabbits, including flushed individuals and roadkills, were documented during the reporting period of December 2012 through December 2013. Personnel observed jackrabbits 14 times and recorded six jackrabbit roadkills (Figure 9). 
HNF- 56710

Revision 0

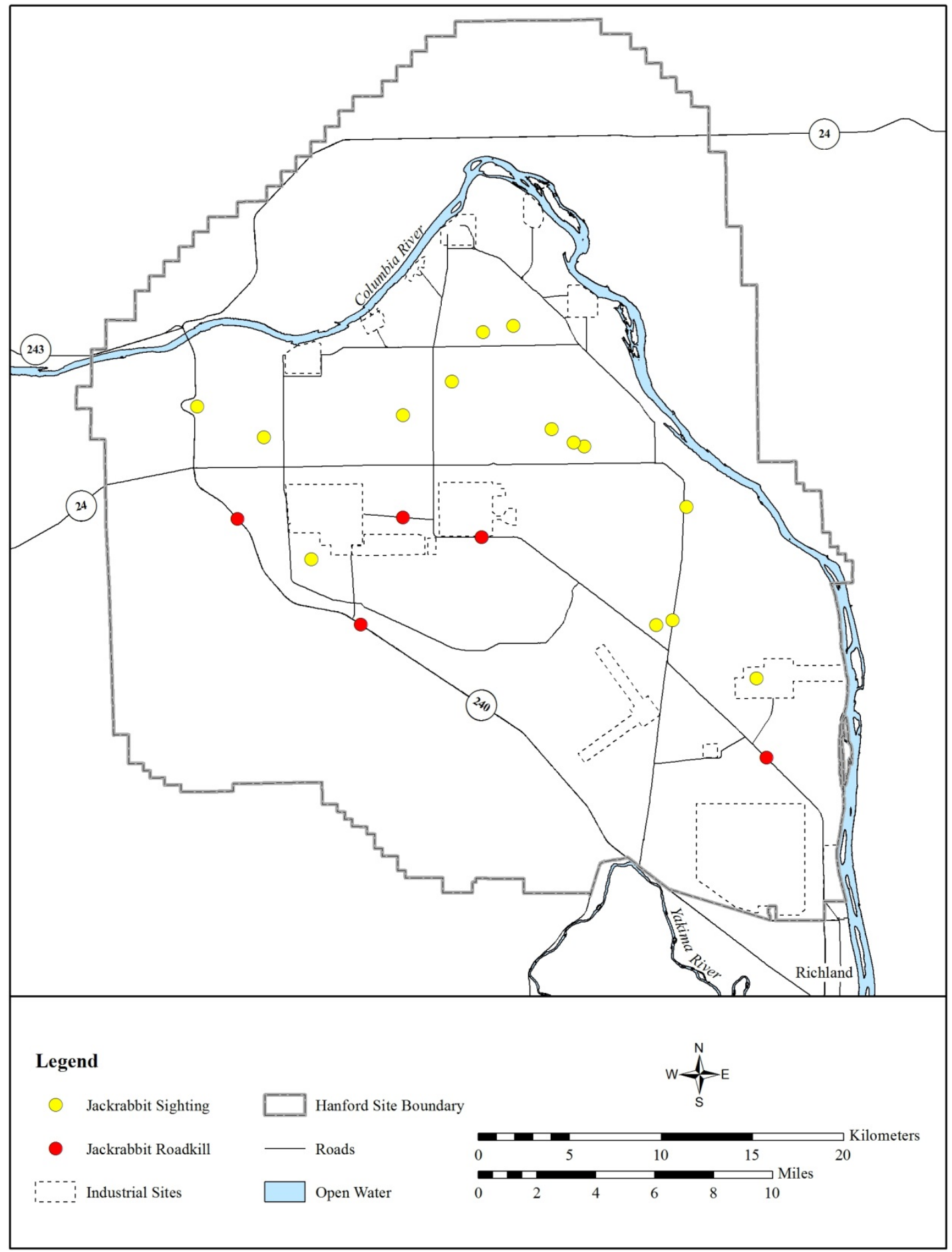

Figure 9. Black-tailed Jackrabbit Sightings and Roadkills on the Hanford Site in 2013 
HNF- 56710

Revision 0

\subsection{Discussion}

The status of the black-tailed jackrabbit population on the Hanford Site was largely unknown at the start of the 2013 survey. Recent jackrabbit data consisted of only occasional and isolated sightings. The data generated by this project begins to show the status and distribution of black-tailed jackrabbits across the DOE-RL managed portion of the Hanford Site.

Snowfall track surveys were restricted by limited snowfall events and quickly melting snow. The weather dependency of this survey type and the 24-hour timeframe after snowfall to complete surveys severely limited the number and extent of surveys that were conducted. The method was not useful for documenting jackrabbits across the Hanford Site given the size of the area and the unpredictability of snowfall in the region. However, this method could be useful in identifying core areas for future camera trap deployments. This could be especially true in habitat types where jackrabbit trails are not readily visible (e.g. heavy cryptogamic crust), or in areas where jackrabbits are present but at low density. In fact, initial deployments of the trail cameras to test effectiveness were conducted in areas where high levels of jackrabbits were detected during snowfall track surveys, and jackrabbits were detected on the cameras during these tests.

Other than occasionally tipping over due to high winds or curious animals, trail cameras functioned well using the deployment techniques described. Camera settings were adjusted seasonally to minimize false-triggering. In the summer, high winds combined with tall cheatgrass (Bromus tectorum) and uneven heating often triggered the camera several thousand times during a single deployment. Other than the encumbrance of sorting through the large number of pictures, this did not affect the usability of the data unless camera cards were completely filled. Sensitivity was reduced slightly to minimize the number of false-triggers.

This project, if continued through completion, would result in a distribution map for jackrabbits on the DOE-RL managed portion of the Hanford Site. The project would be considered complete when all hexagons where jackrabbit presence was confirmed are surrounded by hexagons where jackrabbits were not detected using trail cameras, and when no additional jackrabbit core areas can be located. The map would be useful for determining the habitat characteristics selected by jackrabbits, and the level of connectivity between areas occupied by jackrabbits. The map could also show disconnected jackrabbit populations and areas where opportunities exist to restore connectivity for jackrabbits and other sagebrush obligate species. The habitat characteristics selected by jackrabbits could help guide any restoration efforts.

Incidental observations were tracked during the survey period and a map was generated of these locations. These locations were used to identify potential areas to search for jackrabbit core locations but were not used for the jackrabbit distribution map generated using the camera-trap method. The omission of these data points was to keep that map specific to the detection threshold of the cameratrap method. Different methodologies of jackrabbit detection could produce different distribution 
HNF- 56710

Revision 0

maps, and combining survey methodologies could result in a different threshold of detection being represented within the same map. Identification of trails, tracks, and scat have been used to document jackrabbit presence, but are all less consistent and more dependent on surveyor effort and ability than the use of camera-traps. The camera-trap distribution map, therefore, shows where jackrabbits are present at a high enough level to be detected by the cameras.

The potential exists for jackrabbits to be present, but not detected in hexagons (i.e. false negatives). The detectability of jackrabbits using this method is likely to be density dependent. Dense populations are more likely to be detected while low density populations may be missed (Figure 10). In a case where jackrabbits are suspected in an area, based on the presence of sign, cameras may be redeployed to attempt to correct a false negative. Leaving cameras deployed at a location for multiple days increases the likelihood of detection, while reducing the potential for recording false negatives.

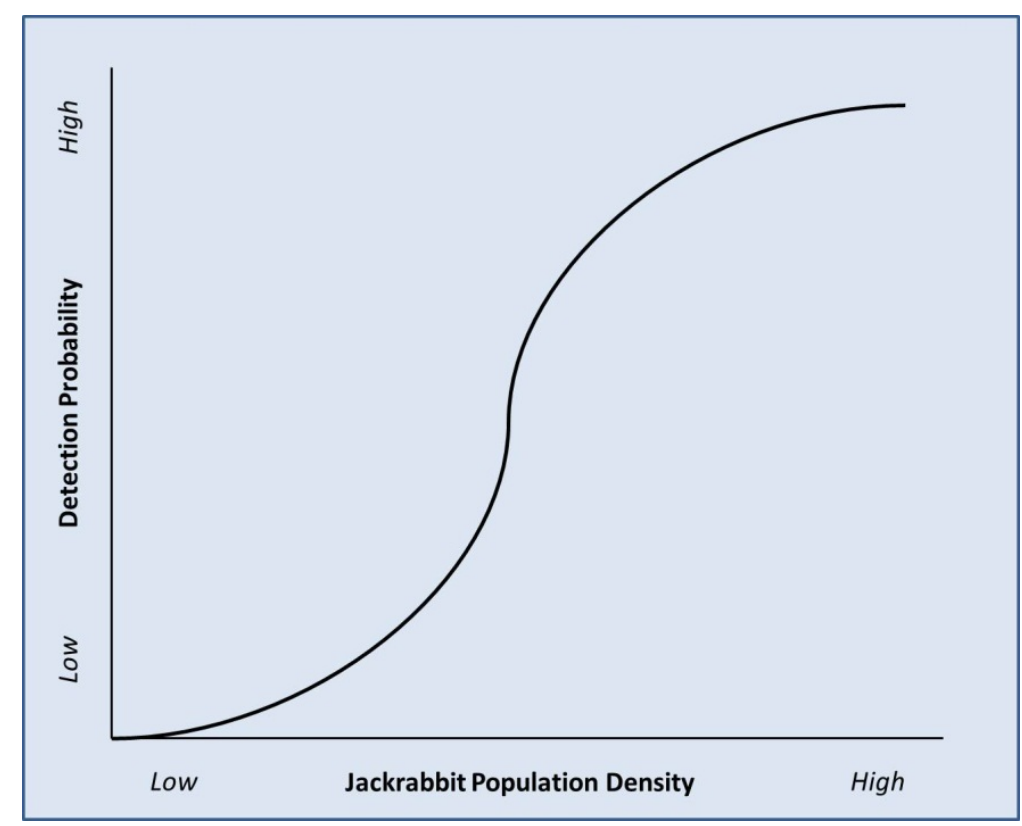

Figure 10. Hypothetical Jackrabbit Detection Probability Curve When Using Trail Cameras

Detection probability can be described by the following equation, where $(p)$ is the probability of a nondetect on a single night, and $(n)$ is the number of monitoring nights, and $\left(p_{n}\right)$ is the overall likelihood of detection.

$$
p_{n}=1-p^{n}
$$

Thus, as the probability of detection during a single night increases, the probability of a non-detect (p) decreases, and as the number of monitoring nights $(n)$ increases, the overall likelihood of detection $\left(p_{n}\right)$ 
increases. Inversely, as the detection probability, and/or the number of monitoring nights increases, the likelihood of recording a false negative (jackrabbits present but not detected) decreases.

Other circumstances that may influence detectability of jackrabbits within a hexagon include variable vegetation types and disturbances such as roadways. It is possible that jackrabbits could use a portion of a given hexagon, but not be present near the centroid due to a change in vegetation type, or a roadway that bisects a given hexagon may be a barrier between an active area and an inactive area. For example, if the centroid of a hexagon falls in a mature sagebrush stand just off of a busy four lane road, while the other side of the road is void of shrubs, it may be inaccurate to represent that jackrabbits exist on both sides of the roadway based on their presence at the centroid. One option for these circumstances includes dividing hexagons into multiple units, and monitoring each unit separately, in order to better represent jackrabbit occupation.

Trail cameras were effective at documenting the presence of jackrabbits, and jackrabbits were by far the most frequently documented species, due to the cameras being focused on suspected jackrabbit trails, but other species were also captured. Elk (Cervus elaphus), mule deer (Odocoileus hemionus), coyotes, birds, mice, and even badgers (Taxidea taxus) were detected with the cameras (Figure 11). Trail cameras could be useful for a variety of other ecological monitoring projects because they minimize man-hours and disturbance to the species being studied while maximizing observation time.

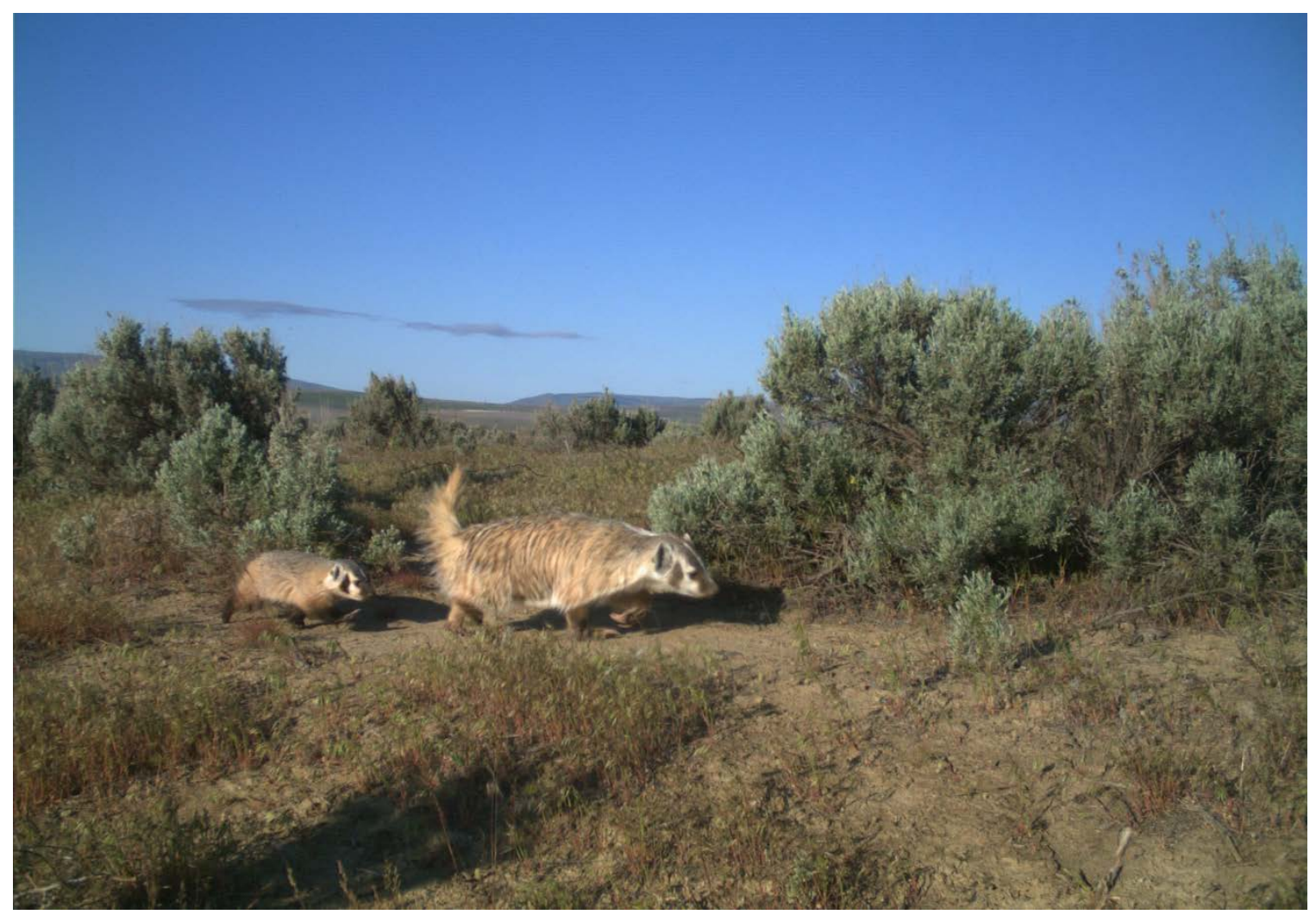

Figure 11. Adult and Juvenile American Badgers Photographed by a Trail Camera During 2013 
HNF- 56710

Revision 0

The FY2013 monitoring effort documented the continued presence of the black-tailed jackrabbit on the Hanford Site, and is helping to establish a population distribution map for this State Candidate species, while also documenting the primary habitats used by jackrabbits on the Hanford Site. Continued monitoring with trail cameras would eventually complete a distribution map for black-tailed jackrabbits on the DOE-RL managed portion of the Hanford Site. This information would be useful during site development planning to minimize potential project-related impacts to black-tailed jackrabbits, as well as other sagebrush obligate species. The data also should be very useful in identifying high-value areas for shrub-steppe connectivity restoration. The data from the FY2013 study could eventually be used to estimate jackrabbit abundance if combined with a mark-recapture study. Habitat surveys in areas occupied and unoccupied by jackrabbits could also contribute to the understanding of black-tailed jackrabbit habitat requirements. Additional monitoring efforts for black-tailed jackrabbits could include snowfall track surveys performed in conjunction with continued trail camera monitoring to document additional portions of the Hanford Site that are occupied by black-tailed jackrabbits. 
HNF- 56710

Revision 0

\subsection{Literature Cited}

Best, T. L, 1996, Lepus californicus, Mammalian Species, 530:1-10.

DOE/EIS-0222-F, 1999, Final Hanford Comprehensive Land-Use Plan Environmental Impact Statement, U.S. Department of Energy, Washington, D.C. Online at: http://energy.gov/nepa/downloads/eis-0222final-environmental-impact-statement-0.

DOE/RL-96-32 Rev 1, 2013, Hanford Site Biological Resources Management Plan, U.S. Department of Energy, Richland Operations Office, Richland, Washington. Online at: http://www.hanford.gov/files.cfm/DOE-RL-96-32-01.pdf.

Comprehensive Environmental Response, Compensation, and Liability Act of 1980, 42 U.S.C. 9601-9675. (P.L. 96-510).

Ferguson, H. L., M. Atamian, 2012, Washington Connected Landscapes Project: Analysis of the Columbia Plateau Ecoregion: Appendix A.3, Habitat Connectivity for Black-tailed Jackrabbit (Lepus californicus) in the Columbia Plateau Ecoregion, Washington Wildlife Habitat Connectivity Working Group. Online at: http://waconnected.org/cp focalspecies landscapeintegrity/.

HNF-54234 Rev. 0, 2012, Black-Tailed Jackrabbit Monitoring Report for Fiscal Year 2012, J. Wilde, C. Lindsey, and J. Nugent, Mission Support Alliance, Richland, Washington. Online at: http://www.hanford.gov/files.cfm/hnf-54234 - rev 00 no coversheets.pdf.

Major, D. J., 1993, Movement Patterns and Habitat Use of the Black-tailed Jackrabbit (Lepus californicus) in South-central Washington, Thesis, Washington State University.

National Environmental Policy Act of 1969, 42 U.S.C. 4321, et seq. (P.L. 91-190).

PNL-8942, 1993, Habitat Types on the Hanford Site: Wildlife and Plant Species of Concern, J.L. Downs, et al., Pacific Northwest Laboratory, Richland, Washington.

TNC (The Nature Conservancy of Washington), 1999, Biodiversity Inventory and Analysis of the Hanford Site: Final Report 1994-1999, Seattle, Washington. Online at: http://nerp.pnnl.gov/docs/ecology/biodiversity/biodiversity 1999.pdf

Washington Department of Fish and Wildlife, 2012, Threatened and Endangered Wildlife in Washington: 2011 Annual Report, Endangered Species Section, Wildlife Program. Washington Department of Fish and Wildlife, Olympia. $7 \mathrm{pp}$. 
HNF- 56710

Revision 0

This page intentionally left blank. 